\title{
PRÓ-SAÚDE, PET-SAÚDE E A FORMAÇÃO DOCENTE - REVISÃo DIALÓGICA DA LITERATURA
}

\author{
PRO-HEALTH, PET-HEALTH AND TEACHER TRAINING - A DIALOGICAL REVIEW \\ OF THE LITERATURE
}

\begin{abstract}
PRO-SALUD, PET-SALUD Y FORMACIÓN DOCENTE - UNA REVISIÓN DIALÓGICA DE LA LITERATURA
\end{abstract}

Mayara Suzy Santana Camelo ${ }^{1}$, Jefferson de Souza Bernardes ${ }^{2}$

\section{RESUMO}

Objetivo: Esta pesquisa se propôs a investigar as práticas docentes e a formação profissional no Pró-Saúde e PET-Saúde por meio de revisão de literatura dialógica. Método: O referencial teórico-metodológico foi o das Práticas Discursivas e Produção de Sentidos. Resultados: A análise dos repertórios linguísticos deu origem a três temas-foco: ensino-serviço, Pró-Saúde e Pet-Saúde, e desafios. No primeiro tema-foco, ensino-serviço, os repertórios identificados trataram das caracterizações e concepções de ensino-serviço, sendo elas: potência, processo em construção e metodologia. Concluiu-se que integrar ensino e serviço possibilitou mudanças significativas nos modos de aprender e ensinar. No segundo tema-foco, os programas Pró e PET-Saúde foram caracterizados enquanto programas indutores de mudanças na formação profissional. Por fim, o terceiro tema-foco referiu-se aos desafios encontrados nas experiências relatadas nos documentos. Conclusão: As iniciativas para as modificações formativas são cíclicas, processuais e em constante construção, fortalecendo e sendo fortalecidas pelas implicações e protagonismo dos/as atores/atrizes envolvidos/as. Entretanto, houve pouca discussão nos documentos identificados sobre a formação docente.

Palavras-chave: Capacitação de Recursos Humanos em Saúde; Sistema Único de Saúde; Planos e Programas de Saúde.

\begin{abstract}
Objetive: This research proposes to investigate teaching practices and professional training in Pro-Health and PET-Health through a dialogical review of the literature. Method: The theoretical-methodological reference is that of the Discursive Practices and Production of Senses. Results: Analyzing the linguistic repertoires gave rise to three focus themes: teaching-service, Pro-Health and Pet-Health and challenges. In the first one, teachingservice, the identified repertoires deal with the characterizations and conceptions of

\footnotetext{
${ }^{1}$ Graduada em Serviço Social pela Universidade Federal de Alagoas (UFAL). Especialista em Gerontologia Social pela (UFAL).
} 
teaching-service, namely: power, process under construction and methodology. It is concluded that integrating teaching and service allows for significant changes in ways of both learning and teaching. In the second theme, the Pro and PET-Health programs are characterized as plans that induce changes in professional training. Finally, the third focus theme refers to the challenges faced within the experiences reported in the documents. Conclusion: The initiatives for formative changes are cyclical, procedural and in constant construction, strengthening and being strengthened by the implications and protagonism of those involved. However, there is little discussion within the identified documents on teachers' education.

Keywords: Health Human Resource Training; Unified Health System; Health Programs and Plans.

\section{RESUMEN}

Objetivo: En este contexto, aquí se investiga la formación profesional y las prácticas docentes en Pro-Salud y PET-Salud por medio de una revisión dialógica de la literatura. Método: La fundamentación teórico-metodológica es la de las Prácticas Discursivas y la Producción de Sentidos. Resultados: El análisis de los repertorios lingüísticos originó tres temas focales: "enseñanza-servicio", "ProSalud y Pet-Salud" y "desafíos". En el primer tema-foco, enseñanza-servicio, los repertorios identificados tratan de sus caracterizaciones y concepciones: poder, proceso en construcción y metodología. Se concluye que integrar la educación con el servicio permite cambios significativos en los modos de aprender y enseñar. En el segundo tema-foco, los programas Pro y PET-Salud se caracterizan como programas inductores de cambios en la formación profesional. Por último, el tercer tema-foco se refiere a los desafíos encontrados en las experiencias relatadas en los documentos. Conclusión: las iniciativas para las modificaciones formativas son cíclicas, procedimentales y están en constante construcción, fortaleciendo y siendo fortalecidas por las implicaciones y el protagonismo de los actores involucrados. Sin embargo, es escaso el debate sobre la formación docente.

Palabras-clave: Capacitación de Recursos Humanos en Salud; Sistema Único de Salud; Planes y Programas de Salud.

\section{INTRODUÇÃO}

O Sistema Único de Saúde (SUS) é o principal ordenador da formação dos profissionais de saúde; coube ao Ministério da Saúde a implementação de políticas e programas que dessem conta dessa demanda. A criação da Secretaria de Gestão em Trabalho e Educação em Saúde (SGTES), no ano de 2003, possibilitou a integração de políticas de gestão, formação e qualificação dos/as trabalhadores/as no âmbito da saúde.

Surgiu daí a Política Nacional de Educação Permanente em Saúde (PNEPS), que objetivava a modificação das práticas e da educação em saúde, visando transformar a rede de serviços e de gestão em rede-escola. 
A relação entre Ministério da Saúde e da Educação foi primordial neste processo. Como produto da articulação entre a SGTES, a Secretaria de Educação Superior (SESu) e o Instituto Nacional de Estudos e Pesquisas Educacionais Anísio Teixeira (INEP), no ano de 2005 surgiu o Programa Nacional de Reorientação da Formação Profissional em Saúde (Pró-Saúde), que visava a reorientação da formação profissional alinhando-se com as necessidades da população, fundamentado na estratégia da Integração Ensino-Serviço ${ }^{1}$. Os eixos norteadores do Pró-Saúde eram a Orientação Teórica, os Cenários de práticas e a Orientação Pedagógica.

A criação do Programa de Educação para o Trabalho para a Saúde (PETSaúde) em 2007 se configurou a partir dos avanços obtidos com o Pró-Saúde e o Programa de Educação Tutorial (PET MEC/Sesu).

Este artigo buscou compreender o que a literatura produz sobre os movimentos que possibilitaram a emergência desses programas e refletir sobre os sentidos produzidos na formação dos/as estudantes, profissionais e docentes. Foi um recorte de projeto de iniciação científica ("Formação e Docência em tempos de políticas indutoras: as experiências no Pró-Saúde e PET-Saúde") que ocorreu entre os anos de 2017 e 2018.

\section{MÉTODOS}

O referencial teórico-metodológico utilizado nesta pesquisa foi o das Práticas Discursivas e Produção de Sentidos, fundamentado no Construcionismo Social. ${ }^{2}$ A revisão de literatura foi orientada pela Revisão Dialógica da Literatura. ${ }^{3,4}$

O construcionismo social posiciona-se de forma pragmática na linguagem, rompendo com a tradição científica representacionista dos fenômenos. A linguagem é entendida como uma forma de ação no mundo, uma prática, por isso o foco em seus usos. É por meio dela que construímos e atribuímos sentido ao mundo em que vivemos. A construção social não é exclusividade de um indivíduo ou grupo, mas sim o que se é produzido a partir do compartilhamento entre diferentes sujeitos, vozes etc. ${ }^{2}$

As práticas discursivas referem-se aos "momentos de significações, de rupturas, de produção de sentido, ou seja, corresponde aos momentos 
ativos de uso da linguagem". ${ }^{5: 26} \mathrm{~A}$ linguagem em uso é ponto de partida para analisar sua performatividade e suas condições de produção, assim como as construções históricas para a emergência dos discursos. A análise é dos repertórios linguísticos, que são as palavras, os vocábulos, as expressões, as figuras de linguagem que configuram a linguagem em uso em determinado contexto.

A Revisão de Literatura Dialógica oferece a possibilidade de entrar em diálogo com textos que estejam conectados: "leio e escrevo a revisão montando conexões, explorando os padrões e as interações relacionais entre os textos. Os organizo para que "conversem" entre si, debatendo e discutindo de maneira respeitosa".3,4

\section{RESULTADOS}

Inicialmente, foram realizados dois movimentos: 1) pesquisa bibliográfica nas bases de dados; e 2) produção de quadros para organizar todas as informações relacionadas a estes documentos, arquivando cada um em modo digital. O Quadro 1 apresenta os procedimentos de busca adotados em cada base de dados.

Quadro 1: Levantamento Bibliográfico por Base de Dados e Descritores.

\begin{tabular}{|c|c|c|c|c|c|}
\hline \multirow{2}{*}{$\begin{array}{l}\text { Base de } \\
\text { dados }\end{array}$} & \multicolumn{4}{|c|}{ Descritores } & \multirow{2}{*}{ Total } \\
\hline & $\begin{array}{l}\text { PET-Saúde } \\
\text { AND Pró- } \\
\text { Saúde }\end{array}$ & \begin{tabular}{|l|} 
PET-Saúde \\
AND Educação \\
Permanente em \\
Saúde
\end{tabular} & $\begin{array}{l}\text { Pró-Saúde } \\
\text { Educação } \\
\begin{array}{l}\text { Permanente } \\
\text { Saúde }\end{array} \\
\text { em } \\
\end{array}$ & $\begin{array}{l}\text { PET-Saúde AND Pró- } \\
\text { Saúde } A N D \text { Educação } \\
\text { Permanente em } \\
\text { Saúde }\end{array}$ & \\
\hline \begin{tabular}{|ll}
\multicolumn{2}{|l}{ Biblioteca } \\
Virtual & de \\
São & Paulo \\
(USP) &
\end{tabular} & 35 & 13 & 24 & 9 & 81 \\
\hline $\begin{array}{l}\text { Biblioteca } \\
\text { Virtual em } \\
\text { Saúde (BVS) }\end{array}$ & 21 & 6 & 9 & 3 & 39 \\
\hline Portal CAPES & 21 & 5 & 6 & 0 & 32 \\
\hline TOTAL & 77 & 24 & 39 & 12 & 152 \\
\hline
\end{tabular}

Fonte: Autores, 2019. 
Os levantamentos bibliográficos da Biblioteca Virtual da Universidade de São Paulo (USP), da Biblioteca Virtual em Saúde (BVS) e do Portal CAPES resultaram em 134 documentos.

Destes, após retirada de repetidos e daqueles que não se coadunaram com os objetivos desta pesquisa, permaneceram 44 documentos para análise.

Os documentos foram organizados em quadros, de acordo com as seguintes categorias: autoras/es, título, data (ano), revista/edição, tipo (artigo, dissertação, monografia ou tese), país, referência e resumo.

Duas dimensões de análise foram importantes para a compreensão dos documentos: 1) análise da produção; 2) análise dos repertórios linguísticos dos títulos e resumos. ${ }^{3,4}$

\section{DISCUSSÃO}

\section{Análise da Produção}

Com base nos 44 documentos encontrados, pôde-se notar que os mais antigos datavam de 2011 (6) e o mais recente de 2016 (1), sendo 2015 o ano em que foram encontrados mais documentos (24), conforme Gráfico 1.

Quanto ao tipo do documento, foram identificados 37 artigos, 5 recursos textuais/editorial e 2 dissertações.

A revista Interface: Comunicação, Saúde e Educação foi a que obteve mais publicações (27), seguida pela revista Ciência e Saúde Coletiva (5), Revista Brasileira de Educação Médica (4), Revista Brasileira de Promoção em Saúde (2). As revistas Investigación y Educación en Enfermaria, Revista da Universidade Vale do Rio Verde e Revista Médica de São Paulo obtiveram 1 publicação cada. 


\section{Gráfico 1: Número de Publicações por Ano}

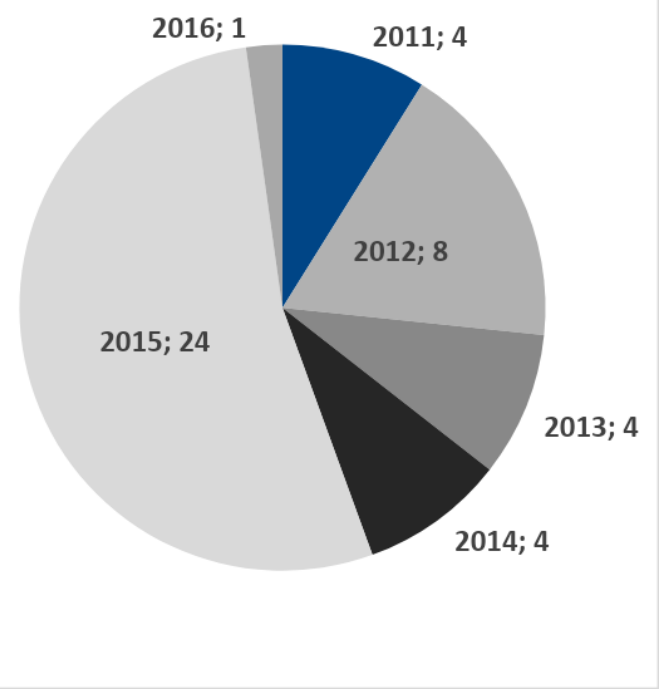

Fonte: Autores, 2019

A Revista Interface foi lançada no ano de 1997 e foi fruto "daquele momento de intensa criação e experimentação em torno de projetos de integração entre a universidade, a comunidade e os serviços de saúde, na formação na graduação médica". ${ }^{6}$ A partir de 2010 , a revista passou a ser caracterizada como dirigida à educação e à comunicação nas práticas de saúde e à formação de profissionais de saúde. Dentre as 27 publicações indexadas nesta revista, 22 foram do ano de 2015. O alto índice de publicações na revista nesse período se deve ao fato de que foi publicado um Suplemento Temático e Livro ("Experiências exitosas de formação em Saúde nas Redes de Atenção à Saúde e a interprofissionalidade: os grupos PET-Saúde e a mudança nos cursos de graduação em Saúde").

Os resultados também apontaram para a concentração de produção dos cursos de Enfermagem e Odontologia em detrimento das outras áreas da saúde como Educação Física, Fonoaudiologia, Serviço Social, Nutrição e Psicologia, conforme Gráfico 2.

A maioria dos documentos possuía um caráter interdisciplinar, englobando autores/as de duas ou mais áreas de conhecimento, o que corroborou com o caráter da revista que obteve mais publicações. Pôde-se 
evidenciar ainda a forte prevalência das áreas de Medicina (em 16 de 23 houve pelo menos um autor/a da área), Psicologia (9/23), Enfermagem e Odontologia ( $8 / 23$ de cada área).

\section{Gráfico 2: Resultados do Levantamento Bibliográfico (USP, CAPES e BVS) por Área de Conhecimento.}

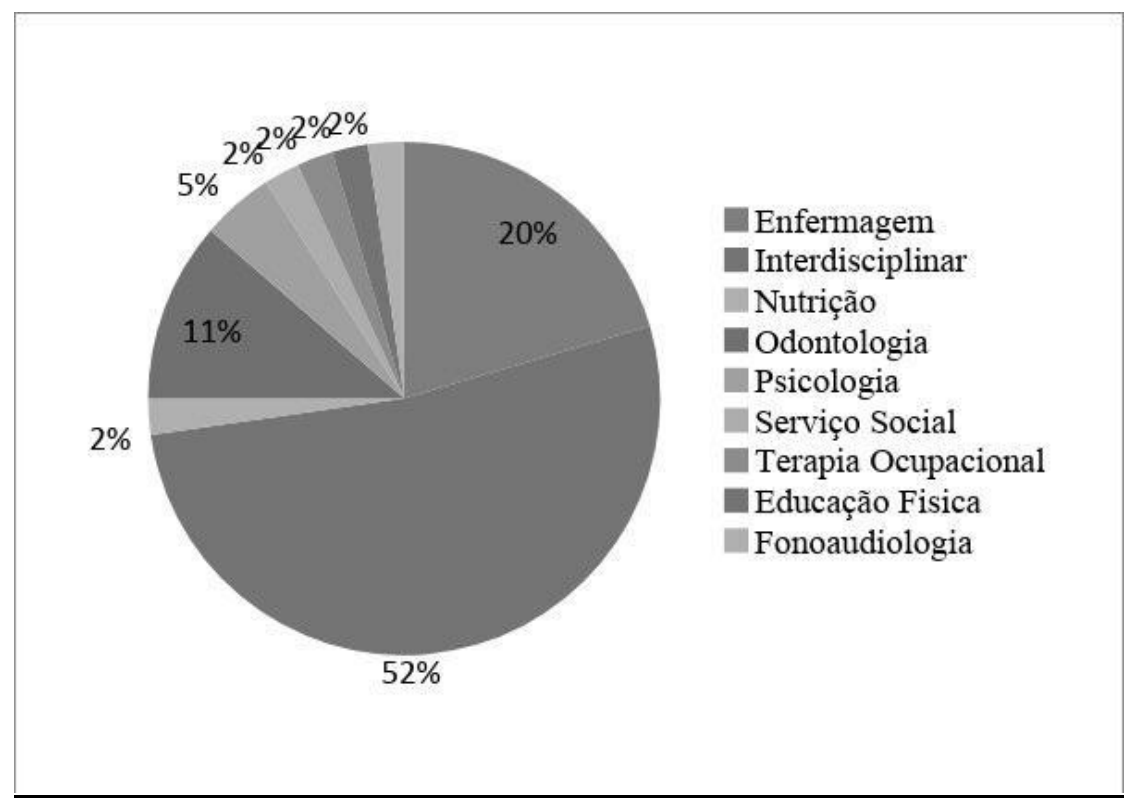

Fonte: Autores, 2019.

Áreas como Terapia Ocupacional, Serviço Social, Fisioterapia, Educação Física, Biologia e Administração também apareceram nos documentos, ainda que com menor prevalência.

\section{Análise dos Repertórios Linguísticos}

A análise dos repertórios linguísticos foi realizada tomando por base os títulos e resumos dos documentos, dando origem a um quadro com três temas-foco: "Ensino-serviço", "Pró e Pet-Saúde" e "Desafios", conforme excerto do Quadro 2. 


\section{Quadro 2: Excerto do Quadro com os Repertórios Linguísticos}

\section{Identificados.}

\begin{tabular}{|c|c|c|c|c|c|}
\hline \multicolumn{3}{|c|}{ Ensino-serviço } & \multirow{2}{*}{$\begin{array}{c}\text { Pró e PET-Saúde } \\
\text { Indutores }\end{array}$} & \multicolumn{2}{|c|}{ Desafios } \\
\hline Potência & $\begin{array}{l}\text { Processo em } \\
\text { construção }\end{array}$ & Metodologia & & Formativos & $\begin{array}{l}\text { Processos } \\
\text { de trabalho }\end{array}$ \\
\hline $\begin{array}{l}\text { A integração } \\
\text { 'ensino- } \\
\text { serviço' é } \\
\text { concebida de } \\
\text { forma } \\
\text { ampliada } \\
\text { como } \\
\text { "ensino, } \\
\text { gestão, } \\
\text { atenção e } \\
\text { controle } \\
\text { social" }\end{array}$ & $\begin{array}{l}\text { "Inexistente } \\
\text { integração 'ensino } \\
\text { - atenção - } \\
\text { gestão - controle } \\
\text { social', ou no } \\
\text { máximo, um } \\
\text { processo } \\
\text { incipiente e em } \\
\text { construção, com } \\
\text { lacunas na } \\
\text { articulação com a } \\
\text { gestão dos } \\
\text { serviços e o } \\
\text { controle social" }\end{array}$ & $\begin{array}{l}\text { "As deficiências } \\
\text { na formação dos } \\
\text { enfermeiros } \\
\text { graduados para } \\
\text { trabalhar em } \\
\text { APS podem } \\
\text { corrigir-se com a } \\
\text { aplicação de } \\
\text { estratégias de } \\
\text { ensino teórico- } \\
\text { prática nas } \\
\text { universidades." }\end{array}$ & $\begin{array}{l}\text { As possibilidades } \\
\text { seriam: o trabalho } \\
\text { interprofissional, } \\
\text { reavaliar as } \\
\text { práticas e a } \\
\text { contribuição com } \\
\text { a formação. Entre } \\
\text { os desafios, } \\
\text { estão: o } \\
\text { despreparo } \\
\text { pedagógico, o } \\
\text { trabalho } \\
\text { interprofissional e } \\
\text { a deficiência na } \\
\text { infraestrutura. }\end{array}$ & $\begin{array}{l}\text { Processos de } \\
\text { mudança da } \\
\text { formação dos } \\
\text { profissionais } \\
\text { da saúde. }\end{array}$ & $\begin{array}{l}\text { Desafios e } \\
\text { possibilidades } \\
\text { no exercício } \\
\text { da } \\
\text { preceptoria. }\end{array}$ \\
\hline
\end{tabular}

Fonte: Autores, 2019.

\section{Primeiro Tema-Foco: Ensino-Serviço}

Neste primeiro tema-foco, os repertórios identificados tratavam das caracterizações e concepções de ensino-serviço. A integração ensinoserviço é trabalho coletivo pactuado e integrado entre diversos atores que compõem a rede de saúde, visando à qualidade de atenção à saúde individual e coletiva, à qualidade da formação profissional e ao desenvolvimento/satisfação dos trabalhadores dos serviços. ${ }^{7}$

Três características básicas sobressaíram na análise deste tema-foco. O Ensino-Serviço foi apresentado como "potência", "processo em construção" e "dispositivo".

Potência refere-se à força, ao vigor, e ao poderio. (8) Foi assim que a integração ensino-serviço foi tratada em alguns documentos: enquanto 
"potência formativa"9 ou "potência latente de transformação dos saberes e fazeres vivenciados em comunhão pelos diferentes atores envolvidos". 10:901

Neste sentido, a política de educação permanente em saúde, deve impactar: no ensino, como importante instrumento para o desenvolvimento técnico profissional e da alteridade com os usuários; na gestão setorial, enquanto política pública governamental; na atenção, no ordenamento e na articulação da rede na prestação de serviços de qualidade, pautados na integralidade e humanização; e no controle social, para o desenvolvimento da autonomia das pessoas e a democratização da condução e do gerenciamento da política de saúde. Forma-se, assim, o "quadrilátero"11 que compõe a formação. Desse modo, o potencial transformador dessa estratégia não deve se limitar às esferas dos mundos do ensino e do trabalho, ampliando-se também para a gestão, a atenção e o controle social. ${ }^{12}$ Ainda, de acordo com essa concepção de quadrilátero, o serviço não se limitaria às práticas de atenção e, sim, também se relacionaria a gerenciar e a conduzir as políticas e a organização do setor; no que tange à comunidade. Este componente também não deve se limitar à integração com a população e, por fim, no campo do ensino, deve-se destacar a articulação com o movimento estudantil como um ator político das IES.

Uma segunda característica deste tema-foco estava em seu caráter histórico. No artigo intitulado "Integração 'Ensino-Serviço' no processo de mudança na formação profissional em Odontologia"12, embora tratassem da ampliação da integração ensino-serviço para atenção-gestão-controle social, relataram que este ainda é um processo incipiente e em construção. ${ }^{12}$

Para os cursos da área da saúde, embora o SUS, atualmente, seja o maior empregador de profissionais destas áreas, ainda há forte ideal de atuar na área privada. Com base nisso, o protagonismo estudantil decai e as relações entre a universidade e os serviços de saúde permanecem fragilizadas. Essa fragilidade surge também no que diz respeito à participação dos serviços nos processos de modificações curriculares dos cursos de saúde. Neste ponto, vale destacar que as relações entre IES e 
serviços devem ser estabelecidas de maneira horizontal, o que implica considerar a interdependência entre ensino e serviço de modo a ampliar as possibilidades de reflexões conjuntas. ${ }^{13}$

Para finalizar este tema-foco, tem-se a última característica que é considerar o ensino-serviço como um dispositivo de articulação teóricoprático que pode suprir as deficiências na formação. ${ }^{14}$ Novamente, tem-se aqui a demanda de substituição de uma metodologia puramente técnica e procedimental a favor de dispositivo que propicie o ensino social e localmente referenciado, que esteja atento às demandas dos serviços e às necessidades de saúde da população, em que a rede passa de espaço de aplicação de práticas para um cenário formativo e transformador. ${ }^{15}$

As mudanças curriculares, portanto, podem transformar a formação profissional em saúde com vistas a propiciar: a educação continuada e permanente dos/as trabalhadores/as da saúde e dos/as professores/as; o desenvolvimento e o aprendizado do trabalho multiprofissional; o fortalecimento do trabalho em equipe; o compartilhamento de saberes e práticas; e a humanização dos serviços de saúde. ${ }^{15}$

Tem-se, portanto, um processo de retro-alimentação no que diz respeito às relações entre a integração ensino-serviço e mudanças curriculares: por um lado, a integração ensino-serviço é necessária para que as mudanças curriculares nos cursos de saúde e dos/as futuros/as profissionais de saúde ocorram; por outro lado, é também necessário que haja essas mudanças curriculares para que a integração ensino-serviço aconteça.

\section{Segundo Tema-Foco: Pró e PET-Saúde}

O segundo tema-foco apresentou o Pró e o PET-Saúde como programas indutores. O Pró-Saúde I foi lançado em 2005 enquanto iniciativa que buscava reformular os modelos de formação até então instituídos - de caráter individual, especialista e hospitalocêntrico, para um processo formativo que estivesse de acordo com as demandas do SUS e considerasse 
as necessidades da população. ${ }^{16} \mathrm{Em}$ sua primeira edição, limitou-se apenas aos cursos de Medicina, Enfermagem e Odontologia. Configurou-se, então, como uma estratégia que visava à integração ensino-serviço prezando pela integralidade no cuidado com o/a usuário/a e reforçando a Atenção Primária. A inserção dos demais cursos da saúde só se deu a partir do ano de 2007, com o Pró-Saúde II.

Azevedo ${ }^{15}$ fez uma revisão acerca dos modelos de governo e as parcerias público-privadas: ao longo da história, os governos oscilaram e ora impulsionavam propostas da iniciativa privada, ora no projeto da reforma sanitária, o que teve impactos diretos na assistência à saúde da população (ora criavam políticas de retração dos direitos sociais ora impulsionavam políticas que garantiam o acesso universal e igualitário, por exemplo). Somente mais recentemente, a partir de 2003, o Ministério da Saúde se propôs a cumprir com a agenda ética-política da reforma sanitária, em que foram destaques: a escolha de profissionais comprometidos com a luta sanitarista para ocupar o segundo escalão do ministério; as alterações na estrutura organizativa do Ministério da Saúde; a convocação extraordinária da $12^{\mathrm{a}}$ Conferência Nacional de Saúde (CNS) e sua realização em dezembro de 2003; e a escolha de representante da Central Única dos Trabalhadores (CUT) para assumir a secretaria executiva do Conselho Nacional de Saúde. Entretanto, quanto à continuidade do projeto privatista houve focalização na precarização e terceirização de recursos humanos e o desfinanciamento da Política de Seguridade Social.

Neste sistema híbrido, a preocupação com a formação profissional foi algo inovador, tendo em vista os programas que foram criados: PROMED, Pró-Saúde e PET-Saúde. Assim, os programas de reorientação profissional na saúde ganharam força.

Como exemplos de programas que incentivavam modificações nos cursos de graduação, podemos citar o PROMED (Programa de Incentivo às Mudanças Curriculares nos Cursos de Medicina); o Ver-SUS (Vivências e Estágios na realidade do SUS), também em 2003, programa que buscava reconhecer o papel formador do SUS, considerando-o enquanto ambiente 
de ensino-aprendizagem; o AprenderSUS, em 2004, que inseriu a integralidade da atenção à saúde como eixo orientador da formação; o Programa Nacional de Reorientação Profissional em Saúde (PRÓ-Saúde) em 2005, tendo sua segunda edição em 2007, juntamente do Programa de Educação pelo Trabalho para a Saúde (PET-Saúde).

A criação do PET-Saúde em 2007 se configurou a partir dos avanços obtidos com o Pró-Saúde e PET MEC/Sesu, de modo a fortalecer a parceria entre os ministérios da Saúde e da Educação junto a Política de Educação Permanente em Saúde. ${ }^{1}$

Os Programas Pró e PET-Saúde são orientados pela integração ensinoserviço e configuram-se em iniciativas que materializam os princípios preconizados pela EPS, promovendo a inserção dos/as estudantes em redes de serviço, diversificando os cenários de práticas, inovando os métodos de ensino, propiciando o trabalho em equipe multidisciplinar, a aprendizagem em serviço e articulando a formação com as necessidades sociais e de saúde da população. ${ }^{17}$

A última edição do PET-Saúde, o GraduaSUS, traçou o movimento inverso ao das edições anteriores: se antes havia a inserção direta nos serviços, agora o movimento é de pensar os processos formativos em prol de mudanças curriculares que estejam alinhadas com as Diretrizes Curriculares Nacionais e a qualificação dos processos de integração ensinoserviço-comunidade. Essa inversão fomentou que os serviços se aproximassem das IES de uma maneira diferente, possibilitando que estudantes, professores/as, preceptores/as, trabalhadores/as e usuários/as se voltassem para dentro da universidade, a fim de revisitar seus projetos político-pedagógicos.

\section{Terceiro Tema-Foco: Desafios}

Com base na análise dos repertórios argumentamos que os documentos apresentaram questões concernentes à própria política de reorientação da formação, aos programas como experiências de integração 
ensino-serviço e relatos de experiências de estudantes, profissionais e preceptores/as dos programas. Nestas questões, foram identificados desafios diversificados nas experiências relatadas: desafios formativos e desafios processuais.

Os desafios formativos foram: os processos de mudança na formação dos/as profissionais de saúde, uma vez que mexe com práticas pedagógicas cristalizadas e relações hierárquicas (professor/a-aluno/a, professor/apreceptor/a, preceptor/a-aluno/a ou, por sua vez, IES-serviço, professor/apreceptor/a); a produção de vínculo, os estágios supervisionados e o trabalho em equipe, cujas oportunidades de encontros com outras áreas só se dão em espaços ainda considerados extracurriculares (projetos de extensão, PET-Saúde, Ligas acadêmicas) ou, em casos curriculares, nos estágios curriculares (ainda que de forma incipiente).

Já os desafios nos processos de trabalho referem-se à preceptoria, aos modos de cuidar e educar e à educação interprofissional, principalmente, pelas (im)possibilidades de estudantes de distintas áreas de conhecimento articularem atividades conjuntas.

Problematizamos este último tema-foco, pois ao identificarmos a dicotomia entre desafios relacionados à formação, por um lado, e desafios relativos aos processos de trabalho, por outro lado, contradiz a própria EPS. O processo formativo (educativo) não deve ser separado dos processos de trabalho, da realidade do dia-a-dia dos serviços. Promover transformações na formação prevê que sejam produzidas novas formas de cuidar e educarse nos próprios serviços. Afirma-se, assim, que as ações formativas fazem parte do processo de trabalho dos profissionais da rede.

Para avançar na formação dos preceptores/as (em algumas áreas, como a psicologia, são chamados de supervisores/as), foi constituído o Plano Nacional de Formação de Preceptores (PNFP). Este plano integrava o eixo de formação do 'Programa Mais Médicos' e visava formar preceptores/as em número suficiente para viabilizar a expansão, com qualidade, de vagas de residência de Medicina Geral de Família e 
Comunidade, de modo a assegurar a universalização do acesso a esta modalidade de pós-graduação aos egressos de medicina a partir de 2019.18

Novamente, vê-se que as iniciativas recaem sob os mesmos públicosalvo: estudantes, profissionais de saúde e preceptores/as. Embora um dos pontos nevrálgicos para a reformulação dos processos formativos seja a modificação das práticas pedagógicas, como podemos identificar, pouco se fala sobre a formação docente.

Foi identificado apenas um documento que propõe uma reflexão sobre os sentidos da docência em saúde. ${ }^{19}$ Tratava-se de um editorial que afirma a importância de políticas e programas voltados para a formação de recursos humanos para o SUS.

Embora haja a demanda de uma formação política, social e localmente referenciada, a formação e o desenvolvimento docente de nível superior ainda ganha pouca atenção no Brasil. ${ }^{20} \mathrm{O}$ campo da docência, então, emerge enquanto universo repleto de sentidos que não necessariamente estão atrelados ao exercício dela. ${ }^{19}$ As inserções de professores/as se dá de diferentes modos: o exercício integral da docência; os/as profissionais que atuam nas suas profissões de origem e se dedicam ao magistério apenas algumas horas por semana; docentes das áreas específicas de pedagogia e licenciaturas que atuam, simultaneamente, nas graduações dos cursos de licenciatura e, também, no Ensino Fundamental e Médio e, por último, os profissionais da área de educação que desenvolvem suas atividades em tempo integral na universidade. ${ }^{21}$

\section{CONCLUSÃO}

A análise dos repertórios linguísticos, produzidos a partir dos documentos encontrados no levantamento bibliográfico, apontou para três temas-foco: ensino-serviço, Pró e PET-Saúde e desafios.

A integração ensino-serviço foi percebida como ferramenta potencializadora de ações, um processo em construção, pois são cíclicas e processuais, e dispositivo de transformações na formação. 
Percebemos um sentido unidirecional dos cursos para a rede nos primeiros programas do PET-Saúde. Entretanto, a última edição inverteu este sentido, propondo transformações das propostas pedagógicas dos cursos.

Foi observado também que os programas mais recentes de incentivo à formação abrangem um público-alvo mais restrito (preceptores/as), novamente deixando de lado a classe docente. Urge, portanto, políticas específicas para a formação docente para o SUS.

\section{REFERÊNCIAS}

1.Silva ALF, Ribeiro MA, Paiva GM, Freitas CASL, Albuquerque IMN. Saúde e educação pelo trabalho: reflexões acerca do PET-Saúde como proposta de formação para o Sistema Único de Saúde. Interface (Botucatu, Online). 2015 [citado 2019 jan. 23 ]; 19(supl 1):975-84. Disponível em: http://www.scielo.br/scielo.php?script=sci_arttext\&pid=S1414-

$32832015000500975 \&$ Ing=en. http://dx.doi.org/10.1590/1807-57622014.0987.

2. Spink MJ, organizadora. Práticas discursivas e produção de sentidos no cotidiano - aproximações teóricas e metodológicas. São Paulo: Cortez; 2013.

3. Walker S. Revisões de literatura: conversas textuais produtivas e transformadoras. Tradução: Thomas Schaeffer Bernardes (2016). Forum: Qualitative Social Research. 2015; 16 (3), art, 5.

4. Montuori A. Literature Review As Creative Inquiry: Reframing Scholarship As a creative process. Journal of Transformative Education. 2005 [cited 2005 oct. 04]; 3 (374). Available from: http:// jtd.sagepub.com/cgi/content/abstract/3/4/374.

5. Spink MJ, Medrado B. Produção de sentido no cotidiano: Uma abordagem teórico-metodológica para análise das práticas discursivas. In: Spink MJ, organizadora. Práticas discursivas e produção de sentidos no cotidiano aproximações teóricas e metodológicas. São Paulo: Cortez; 2013; 2:22-41.

6. Cyrino AP, Lima EA, Garcia VL, Teixeira RR, Foresti MCPP, Schraiber LB. Um espaço interdisciplinar de comunicação científica na Saúde coletiva: a revista Interface - Comunicação, Saúde, Educação. Ciênc. saúde coletiva (Online). 2015 [citado 2019 jan. 23]; 20(7):2059-68. Disponível em: http://www.scielo.br/scielo.php?script=sci_arttext\&pid=S1413$81232015000702059 \&$ Ing $=$ en.

7. Albuquerque VS, Gomes AP, Rezende CHA, Sampaio MX, Dias OV, Lugarinho RM. A integração ensino-serviço no contexto dos processos de mudança na formação superior dos profissionais da saúde. Rev. bras. educ. med. (Online). 2008 [citado 2019 jan. 23]; 32(3):356-62. Disponível em: 
http://www.scielo.br/scielo.php?script=sci_arttext\&pid=S0100-

$55022008000300010 \&$ Ing $=$ en\&nrm $=$ iso\&tlng $=$ pt.

8. Amora S. Minidicionário Soares Amora da língua portuguesa. São Paulo: Saraiva; 1998.

9. Conceição MR, Vicentin MCG, Leal BMML, Amaral MM do, Fischer AB, Kahhale EMP, et al. Interferências criativas na relação ensino-serviço: itinerários de um Programa de Educação pelo Trabalho para a Saúde (PET-Saúde). Interface (Botucatu, Online). 2015 [citado 2019 jan. 23]; 19 (supl 1):845-55. Disponível em: $\quad$ http://www.scielo.br/scielo.php?script=sci_arttext\&pid=S141432832015000500845\&lng=en. http://dx.doi.org/10.1590/1807-57622014.0894.

10. Santos MM, Nétto OBS, Pedrosa JIS, Vilarinho LS. PET-Saúde: uma experiência potencialmente transformadora no ensino de graduação. Interface (Botucatu, Online). 2015 [citado 2019 jan. 23]; 19 (supl 1):893-901. Disponível em: http://www.scielo.br/scielo.php?script=sci_arttext\&pid=S1414-

$32832015000500893 \&$ lng=en. http://dx.doi.org/10.1590/1807-57622014.1345.

11. Ceccim RB, Feuerwerker LCM. O quadrilátero da formação para a área da saúde: ensino, gestão, atenção e controle social. Physis (Online). 2004 [citado 2019 jan. 08]; 14(1):41-65. Disponível em: http://www.scielo.br/scielo.php?pid=S0103-

73312004000100004\&script=sci_abstract\&tlng=pt.

12. Finkler M, Caetano JC, Ramos FRS. Integração "ensino-serviço" no processo de mudança na formação profissional em Odontologia. Interface (Botucatu, Online). 2011 [citado 2019 jan. 08]; 15(39):1053-1070. Disponível em: http://www.scielo.br/scielo.php?pid=S1414-

32832011005000023\&script=sci_abstract\&tlng=pt.

13. Marin MJS, Oliveira MAC, Otani MAP, Cardoso CP, Moravcik MYAD, Conterno L $O$, et al. A integração ensino-serviço na formação de enfermeiros e médicos: a experiência da FAMEMA. Ciênc. saúde coletiva (Online). 2014 [citado 2019 jan. 23]; 19(3):967-74. Disponível em: http://www.scielo.br/scielo.php?script=sci_arttext\&pid=S1413-

$81232014000300967 \&$ lng $=$ en.

http://dx.doi.org/10.1590/1413-

81232014193.09862012

14. Cozer ML, Menezes Brito MJ. Aspectos que facilitam ou dificultam a formação de enfermeiro em atendimento primário à saúde. Invest. educ. enferm. 2011 [citado 2019 jan. 08]; 29(2):238-247. Disponível em: http://www.redalyc.org/resumen.oa?id=105222400009

15. Azevedo V. O PET-Saúde/PUCRS como estratégia para a formação profissional dos trabalhadores do SUS. [dissertação]. Porto Alegre: Pontifícia Universidade Católica do Rio Grande do Sul; 2014.

16. Dias HS, Lima LD, Teixeira M. A trajetória da política nacional de reorientação da formação profissional em saúde no SUS. Ciênc. saúde coletiva (Online). 2013 [citado 2019 jan. 23]; 18(6):1613-24. Disponível em: http://www.scielo.br/scielo.php?script=sci_arttext\&pid=S1413- 
17. Costa MV, Borges FA. O Pró-PET-Saúde frente aos desafios do processo de formação profissional em saúde. Interface (Botucatu, Online). 2015 [citado 2019 jan. 23]; 19 (supl 1):753-63. Disponível em: http://www.scielo.br/scielo.php?script=sci_arttext\&pid=S1414$32832015000500753 \&$ Ing =en. http://dx.doi.org/10.1590/1807-57622014.1057.

18. Brasil. Presidência da República, Subchefia para Assuntos Jurídicos. Lei no 12.871 de 22 de outubro de 2013. Institui o Programa Mais Médicos, altera as Leis no 8.745, de 9 de dezembro de 1993, e no 6.932, de 7 de julho de 1981, e dá outras providências [Internet]. Brasília, DF: 2013. [acesso em 2019 jan. 23]. Disponível em:

http://www.planalto.gov.br/ccivil_03/_ato20112014/2013/Lei/L12871.htm.

19. Oliveira GS, Koifman L. Uma reflexão sobre os múltiplos sentidos da docência em saúde. Interface (Botucatu, Online). 2013 [citado 2019 jan. 23]; 17 (44):211218. Disponível em: http://dx.doi.org/10.1590/S1414-32832013000100017.

20. Batista N. Desenvolvimento docente na área da saúde. Trab. educ. Saúde (Online). 2005 [citado 2019 jan. 23]; 3(2):283-94.

21. Behrens MA. A formação pedagógica e os desafios do mundo moderno. In: Masseto M, organizadora. Docência na universidade. São Paulo: Papirus; 2000; 57-68. 